\title{
Protección a la maternidad: una historia de tensiones entre los derechos de infancia y los derechos de las trabajadoras ${ }^{*}$
}

\author{
Lidia Casas Becerra** \\ Ester Valenzuela Rivera***
}

\begin{abstract}
RESUMEN
Las normas de protección a la maternidad han sido un vehículo para salvaguardar la infancia, la familia, la sociedad toda (el bien común), pero escasamente para proteger a la mujer en cuanto ciudadana. Instar por estas normas ba sido resistida a lo largo del siglo con argumentos que cruzan distintas épocas, como por ejemplo, que proteger a las mujeres tendría un impacto perjudicial en su empleabilidad, aludiendo a factores como el encarecimiento de la mano de obra, la limitación en la gestión de recursos bumanos en la empresa o que el trabajo remunerado femenino es un mal menor, pues abandona las tareas de cuidado y crianza. A este discurso se suma el biomédico que busca la protección de la infancia a través de la lactancia y la salud de los infantes. Solo en los últimos años se recoge en el discurso la equidad de género.
\end{abstract}

Protección a la maternidad - sala cuna - postnatal

\section{Protection of motherbood: a bistory of tensions between the rights of children and the rights of the worker women}

\begin{abstract}
The standards of protection of motherhood have been a vehicle for safeguarding childhood, family and society as a whole (the common good), but hardly to protect women as citizens. Urging by these rules has been resisted throughout the last century with different arguments. For instance, that protecting women would have a detrimental impact on their employability, referring to factors such as rising wage cost; there are limited managerial human resources available in the companies; or that paid work for women is a lesser evil, since they have abandoned the duty of take care of the children. To this discourse is added the biomedical arguments that seeks to protect children through breastfeeding and bealth care. Only in recent years, the discourse of gender equity has been embraced.
\end{abstract}

Motherhood protection - nursery - maternity leave

* Este trabajo representa algunos de los resultados del proyecto de investigación Bicentenario Maternidad, Salud y Trabajo de las Facultades de Psicología, Medicina y Derecho de la Universidad Diego Portales financiado por la Vicerrectoría Académica. Este fue realizado entre julio 2009 a agosto de 2010.

** Abogada, Magíster en Derecho, profesora e investigadora de la Facultad de Derecho de la Universidad Diego Portales, República 105, Santiago de Chile, lidia.casas@udp.cl. Agradecemos la colaboración de la ayudante Camila de la Maza Vent.

*** Abogada, Magíster en Derecho, Directora de Escuela y profesora de la Facultad de Derecho de la Universidad Diego Portales, República 105, Santiago de Chile, ester.valenzuela@udp.cl

Artículo enviado el 26 de agosto de 2011 y aceptado para su publicación por el Comité Editorial el 31 de mayo de 2012. 


\section{INTRODUCCIÓN}

$\mathrm{E}$ 1 surgimiento de la protección a las trabajadoras en la legislación chilena (1917) nace en el contexto de la preocupación por la cuestión social. El postnatal y otras normas de protección son parte del reconocimiento de la lucha del creciente proletariado por mejores condiciones de trabajo y una vida digna en el proceso de industrialización del país.

El modelo de industrialización basado en el hombre-proveedor no repara que las mujeres se encuentran en labores remuneradas como vendedoras, lavanderas, domésticas y posteriormente en la manufactura y servicios ${ }^{1}$. Hutchison indica que en 1912 el $35 \%$ de la fuerza laboral en la manufactura de textiles, ropa y de tabaco estaba compuesta por mujeres ${ }^{2}$.

La demanda por una legislación protectora surgió en constante tensión entre múltiples objetivos: la reproducción de la mano de obra, los indicadores biosanitarios y en escasa medida el mejoramiento de condiciones laborales para las trabajadoras. El reconocimiento de estos derechos sociales tiene en su base el no nacido, el infante y la función reproductiva de la trabajadora, así lo entiende la doctrina ${ }^{3}$. Solo en la última década comienza a aparecer la preocupación por la protección de la familia, la revisión de roles en la crianza y cuidado infantil, su relación con el equilibrio entre maternidad (parentalidad) y trabajo y cuestiones como el apego. Estos cambios de eje surgen en un contexto de cambios culturales que propician la inserción de las mujeres al mundo productivo, en la política y cargos públicos como manifestación de su igualdad en los diversos ámbitos de la vida pública y privada.

Sin embargo, existe una brecha entre los discursos y la realidad. La inserción de las mujeres en el mundo del trabajo no ha cambiado el hecho de que las mujeres sean las principales responsables de las tareas domésticas como concluye el Informe de Desarrollo Humano del PNUD 2010 4 . La Encuesta de Tiempo Libre muestra a su vez que ocho de cada diez mujeres ocupan, al menos, media hora en trabajo doméstico, mientras que en el caso de los hombres solo cuatro de diez, y en el cuidado de otros, solo un 9,2\% de los hombres cuida a otros miembros del hogar a diferencia de un 35,9\% de las mujeres 5 .

${ }^{1}$ Salazar, G., Labradores, peones y proletarios. Formación y crisis de la sociedad popular chilena, LOM, Santiago, 2000, pp. 260-318, y Pieper Mooney, J.E., The Politics of Motherhood. Maternity and women's rights in twentiethcentury Chile, The University of Pittsburgh Press, Pittsburgh, 2009, p. 17.

${ }^{2}$ Hutchison, E., Mujeres, trabajo y maternidad: género y consenso legislativo. Las labores propias del Sexo. Género, políticas y trabajo en el Chile urbano, 1900-1930, LOM, Santiago, 2006, p. 52.

${ }^{3} \mathrm{Al}$ respecto, Irene Rojas Miño señala que "El bien jurídico protegido es el que está por nacer, el recién nacido y el niño. Y ciertamente no es la mujer trabajadora, aunque muchas normas se refieren a ella porque es quien se embaraza $y$, además, en algunas culturas se dedica a la crianza de los hijos". Rojas Miño, I., Manual de Derecho del Trabajo. Derecho Individual, LexisNexis, Santiago, 2004, p. 192.

${ }^{4}$ Programa de las Naciones Unidas para el Desarrollo, Desarrollo humano en Chile. Género: los desafíos de la igualdad 2010, Santiago, 2011, p. 72.

${ }^{5}$ Instituto Nacional de Estadísticas, Encuesta Exploratoria ¿Cómo distribuyen el tiempo hombres y mujeres?, Santiago, 2009, p. 3. En: http://www.ine.cl/canales/chile_estadistico/estadisticas_sociales_culturales/encuesta_tiempo_libre/pdf/enfoque_eut_pag.pdf 
Estos datos van más allá de los prejuicios que influyen en el ingreso de las mujeres en el mundo del trabajo remunerado, el que está construido desde un paradigma masculino.

La tasa de ocupación femenina es de 45,8 mientras que la masculina $72,4^{6}$. El aumento al inicio de los noventa es claro, pero no se puede dejar de considerar la segregación sexual del mercado, las mujeres se concentran en comercio, servicio doméstico y educación ${ }^{7}$.

Nuestra investigación es una indagación histórica que se propone identificar los discursos predominantes en los debates legislativos al momento de la adopción de las normas de protección a la maternidad, para responder si la promulgación de leyes promovía la protección de las trabajadoras y sus condiciones laborales, o solo el bienestar para los niños, su salud y sobrevivencia. Los objetivos de las normas, explícitos e implícitos, tienen consecuencias directas en la protección de los derechos, ya que si solo se protege a las mujeres en tanto medio para proteger a los niños no se las considera como ciudadanas-trabajadoras. Este trabajo culminó antes de la discusión sobre la extensión del postnatal, pero informa los antecedentes históricos para llegar a este punto. Nos centraremos en el análisis de la legislación existente sobre sala cuna, el derecho a alimentar al niño durante la jornada laboral, el descanso maternal, el fuero y licencias parentales.

\section{LA PROTECCIÓN DESDE SUS INICIOS HASTA LA CODIFICACIÓN DE 1931}

Desde la promulgación de la primera ley, sala cuna, se advierten tres momentos distintivos. En cada uno de ellos se observan algunos discursos que se mantienen hasta hoy: las tensiones entre distintos intereses que se van plasmando en las normas y los derechos que están en juego. Estas tensiones reflejan las condiciones sociales, culturales y económicas del país.

\section{a. 1916: La sala cuna y la lactancia}

En 1916 comenzó la discusión sobre el derecho a la sala cuna, la que estuvo vinculada con el amamantamiento culminó con la Ley 3.186 de $1917^{8}$, primera ley en el desarrollo de la protección a la maternidad de las trabajadoras. Este derecho era para toda trabajadora que laboraba en fábrica, taller, o establecimiento con más de 50 obreras mayores de 18 años y contempló las dos fracciones de tiempo de media hora, con cargo al empleador, para alimentar al infante hasta que cumpliera un año de vida. La lactancia y la sala cuna fueron derechos concebidos en forma conjunta, y no como dos derechos independientes. No obstante, se discutió que el número de trabajadoras fuera menor

\footnotetext{
${ }^{6}$ Instituto Nacional de Estadísticas, Compendio Estadístico de Género. Publicaciones del Instituto Nacional de Estadísticas desagregadas por sexo (2007-2009) 2010, Santiago, 2011, p. 71. En: http://www.ine.cl/canales/ menu/publicaciones/calendario_de_publicaciones/pdf/010411/comgen_10010411.pdf

${ }^{7}$ Ibid., p. 72.

${ }^{8}$ Publicada en el Diario Oficial 13 de enero de 1917.
} 
(30), y que ellas pudieran concurrir a sus hogares a amamantar incluso cuando no hubiera obligación de proveer sala cuna ${ }^{9}$. Se excluyó a obreras menores de 18 años y a las mujeres contratadas en el área de servicios, la administración pública y en pequeños talleres, ya que era común el trabajo infantil particularmente en el área de servicios y talleres.

Desde un comienzo, la consagración de estos derechos fue visto como positivo para las trabajadoras, pero perjudicial 'i gravosa' para los empresarios, por la falta de eficacia y el efecto en la empleabilidad de las mujeres. El Senador Ismael Valdés indicó que bastaba que hubiera cuatro o cinco niñas pequeñas para alcanzar el umbral de 30 trabajadoras propuesto, y consideraba que el espíritu de la ley era 'consultar por igual el interés de las obreras i el interés de los industriales' ${ }^{10}$. Las indicaciones sobre rebaja en el número de trabajadoras fueron rechazadas, entre otras razones porque de aprobar la ley las obreras no serían aceptadas en las fábricas ${ }^{11}$.

La discusión de la ley estuvo marcada por la argumentación de las labores propias del sexo y la reproducción. Hutchison señala que la protección fue asegurar 'la raza' o 'la nación chilena' [o la reproducción de la mano de obra]; así a través de la protección a las mujeres se evitaba la alta mortalidad infantil que la ponía en peligro. No había una preocupación por todas las mujeres trabajadoras, sino aquellas que estaban embarazadas, que se encontraban en el puerperio o pudieran amamantar, su condición de madres de hijos pequeños implicaría por extensión la protección de los niños ${ }^{12}$. Existía un interés social o bien público que asegurar y no las condiciones laborales de las mujeres.

\section{b. 1925: La maternidad obrera, el descanso maternal y la lactancia}

Una de las segundas normativas es el descanso maternal, posteriormente adoptado por Decreto Lei 442 en $1925^{13}$ y que comienza a discutirse en $1920^{14}$. Es un avance en materia de descanso maternal y, en lo que respecta a sala cuna, este último amplía la cobertura de trabajadoras (20 en el establecimiento) de cualquier edad o estado civil, pero es un retroceso en cuanto condiciona el permiso de la lactancia a este derecho ${ }^{15}$. Este tiempo se consagró como irrenunciable.

${ }^{9}$ Senado, Legislatura Extraordinaria, Sesión 40, 26 de diciembre de 1916, Documentos 1916-17, p. 351.

${ }^{10}$ Senado, Legislatura Extraordinaria, Sesión 28 de diciembre de 1916, Documentos 1916-17, p. 577.

11 Diputado Irarrázaval, Cámara de Diputados, Legislatura Extraordinaria, Sesión 54, 29 de diciembre de 1916, 1916-1917, p. 1394.

Senado, Legislatura Extraordinaria, Sesión 40, 26 de diciembre de 1916, Documentos 1916-17, p. 351.

Senado, Legislatura Extraordinaria, Sesión 28 de diciembre de 1916, Documentos 1916-17, p. 577.

Diputado Cárdenas, Cámara de Diputados, Legislatura Extraordinaria, Sesión 54, 29 de diciembre de 1916, 1916-1917, p. 1394.

Diputado Irarrázaval, Ibíd.

${ }^{12}$ Hutchison, op. cit., p. 236.

13 República de Chile, publicado el 6 abril de 1925.

${ }^{14}$ Legislatura Ordinaria, Cámara de Senadores, 5 agosto de 1920, p. 652.

15 Artículo 4, D.L. 442,: 'Las madres a que se refiere el artículo anterior [20 trabajadoras con derecho a sala cuna] tendrán derecho a disponer, para amamantar a sus hijos, dos porciones de tiempo...' 
Se estableció el descanso maternal de 60 días (40 antes y 20 días post parto) pagado por el empleador equivalente al $50 \%$ del salario. Se dispuso la inamovilidad de la trabajadora por el tiempo del descanso, la que solo podría ser despedida por 'justa causa' entendiendo que no procedía cuando el despido estaba fundado en el menor rendimiento en razón del embarazo. El texto legal dejaba asentado las instituciones que han permanecido en la legislación social chilena sobre sala cuna-lactancia y descanso maternal, con los primeros pasos en la consagración del fuero maternal como lo conocemos hoy.

El objetivo de la disposición sobre descanso maternal en la discusión parlamentaria fue la protección del recién nacido, un concepto, como se ha dicho, que se repetirá a lo largo de cualquier discusión jurídica, y que además consagraba una amplia protección a la maternidad y la infancia ${ }^{16}$.

Existen antecedentes históricos de propuestas sociales canalizadas por el Senador Malaquías Concha y el diálogo con la SOFOFA mucho antes de la discusión legislativa en la década de 1920. La organización de los empresarios rechazaba, en general, la legislación social pues consideraba que era una restricción a la libertad de trabajo, y sobre las propuestas del descanso hizo una contrapropuesta al mundo social que demandaba doce semanas y en su lugar proponía ocho ${ }^{17}$.

El principal promotor, Senador Malaquías Concha, buscaba asegurar el mayor tiempo posible al descanso postnatal, influenciado por la legislación internacional y los convenios de la recién formada OIT. Esta había adoptado en el Convenio C003 en 1919 la consagración del descanso pre y postnatal de 12 semanas. Malaquías Concha propuso convencer a los senadores de establecer un plazo de seis semanas luego del parto, ya que se consideraba una propuesta de 40 días, proyecto que además no estipulaba su distribución. Por otra parte, otros parlamentarios querían ser flexibles dejando a un reglamento la distribución del descanso ${ }^{18}$.

Al igual que el derecho a la sala cuna y lactancia, un descanso muy extenso era visto como perjudicial para los empleadores y las trabajadoras. Un descanso más breve era percibido como normal, pues, como se argumentó, las parturientas estaban de alta en diez días y aptas para el trabajo ${ }^{19}$. Malaquías Concha contraargumentó que no era lo mismo que una mujer saliera de alta a los diez días y que pudiera levantarse incluso antes, pero que volver a trabajar era una cuestión distinta.

El argumento más convincente para extender por más tiempo el descanso fue la protección del infante y su derecho a ser amamantado, ya que en cifras de la época la mortalidad infantil, en el primer y sexto mes de nacimiento, alcanzaba al $60 \%{ }^{20}$. Pese a los esfuerzos de Malaquías Concha, la distribución de los 40 días de descanso quedó

\footnotetext{
16 Artículo 14 D.L. 442.

${ }^{17}$ Hutchison, op. cit., pp. 241-243.

18 El Senador Aldunate. Ibíd.

${ }^{19}$ Intervención del Senador Juan Enrique Concha, Cámara de Senadores, Sesión 26 de diciembre de 1920,

${ }^{20}$ Ibid. p. 982.
} p. 981 . 
al arbitrio de una reglamentación ${ }^{21}$. Para asegurar el conocimiento y cumplimiento de la ley se previó que las trabajadoras recibieran una libreta con el texto de la ley, y que ella fuera publicada en el lugar de trabajo; sin embargo, la eficacia de la medida sería reducida dado el alto grado de analfabetismo.

\section{c. La codificación: entre la expansión y la reducción de los derechos}

El Código del Trabajo, D.F.L. 178 (1931), consolida en un solo cuerpo legal todas las normas de la legislación social dispersas. Los cambios introducidos expandieron el descanso maternal a seis semanas antes y seis después del parto en conformidad con el Convenio C003 que Chile adoptó ${ }^{22}$. Se mantuvo el subsidio del $50 \%$ del salario de la trabajadora, y su pago era compartido entre empleador y el Seguro Obrero. No obstante, si la trabajadora no tenía derecho a subsidio del Seguro Obrero debería pagarlo íntegramente el empleador ${ }^{23}$. Se consagró la inamovilidad de la mujer por el tiempo que gozara de la licencia de maternidad, y para proceder a su despido debía fundamentarse en una justa causa que no fuera su menor rendimiento ${ }^{24}$.

El Código fija el alcance de las normas protectoras a todos los establecimientos o empresas industriales o comerciales, sean de propiedad fiscal, municipal o particular, y a sus sucursales o dependencias. De esta manera, no sólo hay protección a las obreras sino a todas las trabajadoras, manteniéndose las normas de publicidad para su conocimiento ${ }^{25}$.

La obligación de contar con una sala cuna originalmente se fundó en la cantidad de trabajadoras que la empresa tenía, pero el lenguaje del Código la formuló en la medida de que esas mujeres estuvieran en "el establecimiento" o "faena". En consecuencia, el derecho de alimentación de dos horas y media también se redujo. Las interpretaciones de la Contraloría General de la República y de la Dirección del Trabajo apuntarían en este sentido. Desde la adopción del Código se inicia una interpretación de que la sala cuna es exigible cuando el umbral se completa en la faena y no por el número de trabajadoras contratadas por el empleador, conduciendo a situaciones paradójicas de que hubiera trabajadoras con un estatuto diferenciado dentro de una misma empresa. Con esta formulación y avalada por la interpretación administrativa se redujo el universo de trabajadoras beneficiadas. A la vez se producían otros efectos negativos, cual es la discriminación indirecta, ya que al gravar al empleador por ciertas prestaciones en relación al número de trabajadoras contratadas se buscará restringir el acceso al trabajo para evitar el nacimiento de la obligación.

La consagración de estos derechos y su cumplimiento también fueron parte de una agenda social y política del Movimiento de Emancipación de la Mujer Chilena (MEMCH) que los vieron como derechos y no como privilegios. Las memchistas, feministas sufragistas

\footnotetext{
21 Ibid.

22 Artículo 309 del Código del Trabajo, D.F.L. 178.

23 Artículo 310 del Código del Trabajo, D.F.L. 178.

24 Artículo 2 D.L. 442.

${ }^{25}$ Artículo 308 del Código del Trabajo, D.F.L. 178.
} 
y socialistas entendieron la explotación de las mujeres en su doble condición, por ser mujeres y trabajadoras, y abrazaron la preocupación por los altos índices de mortalidad infantil ${ }^{26}$.

Es posible que la utilización de otras formas de contratación como el trabajo a domicilio de las costureras de los talleres de confección quedaran excluidas si se consideraba que trabajar en el hogar no impedía el amamantamiento, el catalizador de la protección.

La mantención y protección de la lactancia tiene un rol central para mejorar los indicadores de mortalidad infantil en la política sanitaria mediante la legislación social y posteriormente la sanitaria ${ }^{27}$, y por lo mismo vale recordar que coetáneamente se prohibió la contratación de nodrizas en el amamantamiento de hijos ajenos por el descuido al hijo propio.

La tensión entre familia-trabajo y los roles de género asignados a hombres y mujeres estuvieron siempre en conflicto; el trabajo asalariado era visto como una fuente de ingreso decente para las mujeres ${ }^{28}$, alejadas de la posibilidad del comercio sexual por necesidad económica ${ }^{29}$. Pero el trabajo remunerado fuera del hogar tenía para los católicos sociales la potencialidad de socavar la responsabilidad de las mujeres en el cuidado de sus hijos ${ }^{30}$, opinión que también compartía el movimiento obrero.

Las leyes que se dictan en esta primera etapa del siglo XX y particularmente alrededor de 1925 y antes de la adopción del Código del Trabajo en 1931 perfilan una legislación intervencionista del Estado, la que provocó, a juicio de Hutchison, relaciones laborales más precarias y mayor explotación. Ella explica que las mujeres requerían los ingresos y por menores que fueran seguirían trabajando durante el embarazo ${ }^{31}$. La ineficacia de la ley también se producía porque las leyes o decretos leyes resultaban insuficientes cuando no se dictaba la reglamentación que debía acompañarlas ${ }^{32}$, como habría sido el caso de las primeras leyes. Hutchison da cuenta que en 1926 en las inspecciones realizadas por la Oficina del Trabajo -anterior a la inspección- el $75 \%$ de los talleres y fábricas no habían asegurado la sala cuna para sus trabajadoras ${ }^{33}$. Todo ello sin contar con la alta proporción de trabajadoras a domicilio que eran pagadas por pieza cuyas condiciones laborales quedaban fuera del espectro de protección social.

Díaz Salas se refiere a una sentencia de la Corte Suprema de 1950 que declaró sobre estas trabajadoras: "El derecho a la licencia también lo tienen las empleadas que

${ }^{26}$ Pieper Mooney, J. E., op. cit., p. 33.

${ }^{27} \mathrm{El}$ art. 44 del Código Sanitario en 1931 expresa que la madre estará obligada a amamantar a su hijo por sí misma hasta los cinco meses de edad, y declarando que la leche materna es de propiedad del hijo, señalaba: “...No podrá ella amamantar niños ajenos mientras el suyo no haya cumplido dicha edad....” El Código fue adoptado por el D.F.L. 226 del 15 de mayo 1931. Una norma similar subsiste, artículo 18, sin que establezca el tiempo de amamantamiento.

28 Así lo concebían los industriales de la SOFOFA, Hutchison, op. cit., pp. 238-239.

${ }^{29}$ Salazar, G. y Pinto, J., op. cit., p. 160.

${ }^{30}$ Hutchison, op. cit., p. 242.

31 Ibid., p. 237.

32 Ibid., p. 238.

${ }^{33}$ Hutchison, op. cit., p. 256. 
trabajen en su domicilio. La mención que se hace en el artículo 2 de 'establecimientos industriales o comerciales' solo se refiere a la prohibición de trabajar en ellos y no significa que el derecho a descansar solo favorece a quienes prestan sus servicios en estos establecimientos" 34

Pieper critica la consagración de los derechos a sala cuna y lactancia, puesto que no se consideró el contexto de vida de las mujeres, las dificultades de trasladar a infantes hasta el lugar de trabajo, o el estigma asociado a dejar a los hijos en "abandono" en la sala cuna, por lo cual buscaban formas alternativas de cuidado infantil o que incluso al no poder amamantar daban otros alimentos a sus hijos. Por lo mismo, desde el ámbito biomédico se buscaba restringir las labores remuneradas de las mujeres fuera del hogar ${ }^{35}$. De allí que Molina Bustos sostenga que la profesión médica asumió un rol ambivalente conciliador entre un Estado protector/benefactor y opresor/controlador cuando se refiere a contener los conflictos sociales ${ }^{36}$ y gran promotor de legislación social. En este caso, jugaba entre la protección y controlador de madres inadecuadas en su rol de cuidado y crianza.

\section{LA TRANSFORMACIÓN DE LA PROTECCIÓN}

\section{A LA MATERNIDAD DESDE 1931 A 1973}

Desde esta primera etapa en la consagración de las normas de protección a la maternidad le sigue un periodo en que se promueven reformas en relación con las condiciones laborales de las mujeres que permitan reducir las tensiones entre la maternidad y el trabajo remunerado. Sin embargo, la primera infancia sigue siendo el hilo conductor de los cambios, se consolida el rol de la comunidad médico-legislativa y el discurso biomédico de protección a la salud de los niños a través de la lactancia y las normas de Derecho del Trabajo.

\section{a. Extensión del postnatal: de la discrecionalidad médica a la consagración del derecho}

La mantención de un postnatal de seis semanas se mantuvo inalterada desde 1925 hasta mediados de los sesenta en la legislación laboral nacional. No obstante, hubo extensión del postnatal de seis a 12 semanas cuando la opinión médica así lo dispusiera. La Ley $16.434^{37}$ estableció en el Código del Trabajo que "si el cuidado del niño lo requiere, el Servicio Médico prolongará por seis semanas más el subsidio maternal

${ }^{34}$ Díaz Salas, J., Legislación Social. Código del Trabajo, Tomo V 1949-1951, Editorial Nascimento, Santiago, 1952, p. 44 citando Corte Suprema, recurso de queja, Informe 1410 de la Corte de Alzada de Santiago, García y Cía., sentencia 6 de marzo 1950.

35 Pieper Mooney, op. cit., p. 26. La autora cita una serie de problemas que identifica Victoria García Capenetti en el Boletín Médico Social de la Caja del Seguro Obligatorio 4, N 44-45, pp. 15-25, en 1938.

36 Molina, C., Institucionalidad Sanitaria Chilena 1889-1989, LOM, Santiago, 2010, pp. 56-57.

${ }^{37}$ Publicada en el Diario Oficial el 26 de febrero de 1966. 
posnatal”, y con ello, la inamovilidad laboral durante este período. Esta fórmula tenía un antecedente en la Ley 10.383 que regulaba la Ley del Seguro Obrero ${ }^{38}$, que en su artículo 32 complementaba la extensión del postnatal a seis semanas y con el derecho a alimento suplementario a la mujer lactante a partir de la séptima semana postparto ${ }^{39}$. La discusión legislativa da cuenta del recelo de algunos legisladores a la comunidad médica cuyos miembros eran criticados por la liviandad en el otorgamiento de las licencias ${ }^{40}$.

Se trataba claramente en sus inicios de una obligación protectora a la trabajadoramadre-proletaria, pues las "empleadas" tenían sus propias normas previsionales. La moción no nace como una preocupación por todos los infantes sino por los prematuros. El Diputado Gustavo Monckeberg del Partido Nacional, ginecoobstetra, con su propuesta en 1963 buscó asegurar que el descanso maternal se extendiera al doble cuando el parto fuese de prematuro, ya que observaba un mayor número por razones 'sociofisiológicas' y de relevancia estadística posiblemente por el trabajo de la mujer ${ }^{41}$, y, que por ello, los cuidados al recién nacido no serían los mismos para un prematuro quien requiere una atención preferencial que al que ha nacido de un parto normal ${ }^{42}$, buscando que el prematuro alcanzara un peso equivalente a un infante de término.

Esta moción fue aprobada por unanimidad en la Comisión de Asistencia MédicoSocial e Higiene no sólo por razones humanitarias, sino, en palabras de su proponente, por "eugenesia positiva y de toda justicia, porque no hace sino devolver el reposo que perdió la madre por haber sido prematuro su parto" ${ }^{43}$. La discusión legislativa se remitió a asegurar la certificación de los partos prematuros; algunos querían que fuesen acreditados por "un médico competente" ${ }^{44}$, mientras para otros les bastaba el certificado médico y no exigirse el que fuese de un ginecoobstetra por su bajo número, lo que pudiera dificultar el ejercicio del derecho ${ }^{45}$. El poder de certificar el parto prematuro era visto como un poder demasiado laxo para los médicos, y por ello, algunos buscaron que fuera el médico del domicilio de la parturienta, como dijo el Senador radical Ahumada, 'pues sabemos la latitud con la que se entregan algunos certificados. A mi juicio, si la certificación en referencia podrá ser otorgada por cualquier médico se burlará el espíritu de la ley.' y agrega que los certificados falsos deben ser sancionados ${ }^{46}$. Al Senador le

\footnotetext{
38 Publicada en el Diario Oficial el 8 agosto de 1952.

39 Artículo 32.

${ }^{40}$ Este es un argumento que ha subsistido hasta hoy en relación con la licencia por enfermedad de hijo
} menor de un año y que fue discutido a la luz de la extensión del postnatal hasta los seis meses.

${ }^{41}$ Historia de la Ley 16.434, Legislatura Extraordinaria, Cámara de Diputados, 20 de noviembre de 1963, p. 1444.

42 Ibid.

${ }^{43}$ Historia de la Ley 16.434, sesión $8^{\text {a }}$ del 15 de junio de 1965, Cámara de Diputados. Legislatura Ordinaria, Vol. I, 1965, p. 925.

${ }^{44}$ Indicación del Senador Víctor Contreras, en Senado Legislatura Ordinaria 1965, Vol. I, Sesión 33 del Senado, 17 de agosto de 1965, p. 2385.

${ }^{45}$ Intervención del Senador radical Ahumada, Ibíd.

${ }^{46}$ Intervención del Senador DC Foncea, Diario de Sesiones del Senado, Legislatura Ordinaria 1965, Vol. I, Sesión 33 del Senado, 17 de agosto de 1965, p. 2386. 
respondió una senadora comunista quien dijo 'la mujer del pueblo' no es atendida por médicos sino por matronas ${ }^{47}$, cuestión que ocurre hasta la fecha ${ }^{48}$.

Un Senador conservador señaló que era razonable exigir seguridad en el certificado médico, y propone que sea el reglamento el que decida la materia ${ }^{49}$. Mientras tanto el Senador Allende (PS) objeta las aprensiones sobre los certificados falsos, señalando que no comparte el argumento de que numerosos médicos los emitan, y que cree que en ésta, como en otras profesiones, 'existe un superior sentido de la responsabilidad'50.

Más allá de la discusión sobre el rol de los médicos, se producen diferencias entre la Comisión del Trabajo en el Senado y el Ejecutivo, ya que la propuesta solo tendría efectos para el parto prematuro y beneficiaría a un grupo de trabajadoras. Finalmente se plasmó la idea de una protección más amplia y que fuese por la necesidad de todo infante, lo cual estaría determinado por un profesional de la salud.

En 1972 se amplió el descanso postnatal sin necesidad de certificación médica a través de una iniciativa del Ejecutivo como un derecho universal sin sujeción a la decisión del médico de turno por un período de 12 semanas $^{51}$. Nuevamente, el objetivo fue asegurar la lactancia natural por su especial valor en la protección de salud del niño ${ }^{52}$, y tal como lo manifestaron en el debate, la evidencia indicaría que hay un mayor porcentaje de muertes en los primeros meses de vida ${ }^{53}$.

El argumento biomédico fue presentado por la Senadora Carrera, médica, quien señaló la necesidad de reducir los indicadores de mortalidad infantil a través de la lactancia si la mujer cuenta con más tiempo con el recién nacido para su amamantamiento y cuidado, ello es vista como "otra forma proteger la salud de los niños y, por ende, a las generaciones futuras, pues posibilitará dotarlas de mayor calidad biológica" 54 . Ella apunta a que algunas opiniones médicas postulan que 'al ajetreo de la vida moderna, las

${ }^{47}$ Intervención de la Senadora Campusano, Ibid, p. 2386.

${ }^{48}$ Las cifras de atenciones de partos en el sistema público de salud muestran que a nivel nacional el $62 \%$ son partos vaginales, los que son atendidos por matronas, y el resto son partos por cesáreas, los que son atendidos por ginecoobstetras. En esta materia hay dos Chile, el del sistema público de salud y el privado. En el primero hay diferencias regionales, pero es un rasgo común en el sistema que todo el control pre, postparto y el parto mismo sea atendido por matronas, en consecuencia partos vaginales, mientras que en el sistema privado la mayoría de los partos son por cesáreas y la atención la realizan médicos. Véase Dides, et al., Salud Sexual y Reproductiva en Chile 2007: actualización de datos estadísticos, Facultad Latinoamericana de Ciencias Sociales, Santiago, 2008, pp. 36-37, y Schiappacasse, Verónica et al., Chile: Situación de la Salud y los derechos sexuales y reproductivos, Instituto Chileno de Medicina Reproductiva, Corporación de Salud, Instituto Chileno de Medicina Reproductiva y Políticas Sociales y Servicio Nacional de la Mujer, Santiago, 2003, p. 52.

${ }^{49}$ Intervención del Sen. Bulnes Sanfuentes, Diario de Sesiones del Senado, Legislatura Ordinaria 1965, Vol. I, Sesión 33 del Senado, 17 de agosto de 1965, p. 2387.

${ }^{50}$ Intervención del Sen. Allende, Ibíd. p. 2389.

${ }^{51}$ En Historia de la Ley 17.928, publicada en el Diario Oficial 10 de mayo de 1973, Sesión 30, Diario de Sesiones del Senado, 19 de julio de 1972, pp. 1939-1940.

52 Mensaje del Ejecutivo, Diario del Senado, Sesión 30, 19 de julio de 1972, p. 1939.

53 Ibid.

${ }^{54}$ Historia de la Ley 17.928, Diario de Sesiones del Senado, 12 de diciembre de 1972, p. 1840. 
preocupaciones y el nerviosismo' han reducido la lactancia materna ${ }^{55}$. Este argumento estuvo igualmente presente a propósito del permiso para alimentar, extender el derecho a sala cuna (dos años) y la creación de jardines infantiles que se había discutido durante el gobierno de Frei Montalva.

\section{b. De la lactancia al derecho a alimentar y el derecho a sala cuna}

El derecho a sala cuna/derecho a amamantar se mantuvo inalterado de 1917 hasta los sesenta. El empleador debía contar con una sala cuna si tenía 20 o más trabajadoras en su establecimiento, y eran beneficiarios los niños hasta que cumplieran un año de edad aplicable solo a las obreras. En 1966 se modifica la ley. Se impone la obligación a los empleadores hasta que el niño cumpla dos años y expresa que "la Dirección del Trabajo podrá ordenar el establecimiento de salas cunas aún en aquellas industrias que ocupen menos de veinte obreras y empleadas, si las circunstancias existentes en la respectiva industria así lo aconsejaren" 56 .

La propuesta presentada por el Diputado médico Monckeberg del Partido Nacional en 1964 insta a la modificación pensando en el cuidado de los niños cuando alcanzan la edad de un año y quedan en desprotección: las madres deben optar por dejarlos solos o prácticamente solos, o renunciar a sus trabajos al no contar con cuidado infantil ${ }^{57}$. Se consideró que los niños a la edad de dos años ya estaban más desarrollados para poder ser cuidados por otras personas. Haciéndose cargo de los mayores costos que implicaría para los empleadores, Monckeberg responde que 'La mayor contribución ... se compensa en exceso con la contribución moral que proporcionarán a la sociedad, lo que redundará en definitiva, en beneficio común de patrones y empleados" 58 .

Hay conciencia de que no se trata de contar con la sala cuna para 'amamantar', pues "no es corriente que una guagua sea amamantada hasta los dos años, aunque puede suceder" 59 . Así la voz 'amamantar' se usa en un sentido amplio "porque no se puede privar a una madre, por el solo hecho de que la naturaleza no le ha dado la cualidad de todas las madres, de poder alimentar a sus criaturas en su primera edad con su propia leche, de la posibilidad de tenerlas cerca de sí a la hora de la comida, a fin de alimentarlas con la mayor solicitud y darles el cuidado necesario" 60 . Este punto es relevante pues incluso varios años después de la modificación legal la Dirección del Trabajo y la Contraloría debían dirimir la aplicación de la ley restrictiva ${ }^{61}$.

${ }^{55}$ Ibid.

${ }^{56}$ Ley 16.511 publicada en el Diario Oficial el 26 de julio de 1966.

${ }^{57}$ Historia de la Ley 16.511, Cámara de Diputados, sesión 57, 15 de abril de 1964, en Cámara de Diputados. Legislatura Extraordinaria, Vol. IV 1963-1964, p. 4096.

58 Ibid.

59 Intervención del Diputado DC Valenzuela V., Cámara de Diputados, Legislatura Ordinaria, Vol. 1, sesión 8 de junio de 1966, p. 492.

${ }^{60}$ Intervención del Diputado radical Juan Rodríguez en la sesión 4, 8 de junio de 1966, p. 492.

${ }^{61}$ Véase, por ejemplo, Dictamen de la Dirección del Trabajo No 7486/171 del 19 de octubre de 1990 en Revista Jurídica del Trabajo 558, Sept. 1991, p. 76. Dictamen 33.457 del 28/12/84. En el Dictamen 16.965 de 13/07/92, la Contraloría discurre en la discriminación que se produce en el caso de que el niño fuese adoptado. 
Se instó al aumento de las sanciones en caso de incumplimiento, promoviendo la facultad de la Inspección del Trabajo para ordenar la creación de salas cunas en "aquellas industrias que cuenten con menos de 20 trabajadoras" 62 . La historia de la ley menciona la presencia en la discusión del Fiscal de la Dirección del Trabajo, y la tensión existente con la interpretación y alcance de la voz 'establecimiento' o industria para efectos del cumplimiento de la norma. No pudimos establecer si la facultad que la ley le franqueaba a la Dirección del Trabajo fue alguna vez utilizada. Esta disposición fue posteriormente derogada.

La discusión de la sala cuna está íntimamente relacionada con el cuidado infantil y la creación de la Junta Nacional de Jardines Infantiles (JUNJI, Ley 17.301) ${ }^{63}$, organismo que posteriormente asume la vigilancia del cumplimiento de las normas sobre salas cuna del Código del Trabajo. El cuidado infantil se discutía por dos vías, una legislación social y política pública, y otra por el régimen del derecho laboral. Una con carga a impuestos generales y la otra con cargo al empleador.

La ley de la creación de la JUNJI, propiciada a mediados de la década de los sesenta a partir de una moción de la Diputada María Inés Aguilera (DC), pone especial acento en la existencia de espacios de cuidado infantil para las trabajadoras como un segundo hogar, y así lo declaró al momento de aprobarse la moción, resaltando un discurso de reconocimiento de que se trata de una cuestión de mejoras para la vida de las trabajadoras,

“... este proyecto es un homenaje de las mujeres de este Parlamento a la madre trabajadora, a la madre que sufre y espera. Esta es nuestra respuesta: les entregamos este proyecto que, si bien es cierto no es lo que hubiéramos querido, por lo menos reconocemos honestamente que constituye un gran avance, puesto que los hijos de las mujeres que salen a trabajar ahora podrán tener un segundo hogar donde quedarse" 64 .

\section{c. De la causa justa al fuero}

Hubo otras instituciones que en este período de consolidaron, entre ellas el fuero maternal. La trabajadora embarazada contaba con una protección reforzada de inamovilidad, primero por condición de su embarazo, y luego por descanso y no podría ser despedida sin justa causa, la que no podría ser la menor productividad producto de su embarazo ${ }^{65}$.

Durante la década de los sesenta y en ocasión de la tramitación de la extensión del postnatal, las Diputadas María Maluenda y Gladys Marín, ambas del PC, propusieron una

${ }^{62}$ Informe de la Comisión de Trabajo y Previsión Social recaído en el proyecto sobre funcionamiento de sala cuna, en Senado, Diario de Sesiones, Senado, Legislatura Ordinaria, 18 de agosto de 1965, p. 2589.

63 Publicada en el Diario Oficial el 22 abril de 1970.

${ }^{64}$ Historia de la Ley 17.301, alocución de Diputada María Inés Aguilera, Cámara de Diputados, Sesión 33, 29 abril de 1969, p. 60.

${ }^{65}$ Artículo 2 del Decreto Lei 442 y posteriormente en el artículo 310 del D.F.L. 178. 
indicación para extender el período del fuero maternal, de seis meses antes y seis meses después del parto ${ }^{66}$, apoyadas por la bancada de la DC en la Cámara de Diputados ${ }^{67}$. El fuero es nuevamente presentado como un protección al que está por nacer, "Como democratacristianos, estamos totalmente conscientes de la necesidad de que tiene la mujer trabajadora, justamente durante este período tan difícil, de contar con las garantías suficientes para gozar de estabilidad en su trabajo y de protección para el hijo que está por nacer" ${ }^{68}$.

El eje era la discriminación en razón de la maternidad. La Senadora Campusano (PC) hace notar las prácticas discriminatorias: "Basta leer los avisos que exhiben numerosas fábricas, "Se recibe solo a operarias solteras" ${ }^{69}$. Sin embargo, la discusión del fuero fue rechazada en el Senado por la bancada DC, algunos de sus miembros creían que las mujeres estarían en constantes períodos de inamovilidad, pues sostenían que era común que las mujeres jóvenes tuvieran muchos hijos, por lo cual no les convencía la medida. La inamovilidad fue criticada como la creación de un problema para las mujeres; el Ejecutivo rechazó la propuesta argumentando que el fuero no favorecería sino que impediría el ingreso de las mujeres casadas a los puestos de trabajo ${ }^{70}$. Las organizaciones de trabajadores rechazaron las observaciones/veto del Ejecutivo e increparon al propio Presidente. El rechazo del Departamento Femenino de la Central Única de Trabajadores es elocuente:

“¿Puede existir algo más sagrado que hacer leyes para las madres que incorporadas a la producción, cumplen a la vez con la excelsa misión de ser madres? ¿Puede haber algo más inmenso que procurar la estabilidad del trabajo de las obreras y empleadas que siendo madres más necesitan de un salario o sueldo para alimentar a sus hijos?... En la fundamentación del Ejecutivo [...] plantea que de prolongarse la inamovilidad de la madre trabajadora a un año en vez de favorecerla, discrimina en su contra, pues los empleadores y patrones evitarán contratar a mujeres casadas”. Nos preguntamos, con la autoridad que tenemos al ser ciudadanas chilenas, dirigentes sindicales, trabajadoras y madres: ¿Quién gobierna este país? ¿Usted señor Frei, o los empleadores o patrones? Su fundamentación es débil, carente de humanidad, reaccionaria, impropia de lo que su gobierno y partido han sostenido, de que en Chile hay revolución y libertad. [...] el Ejecutivo dice que se ha manifestado una apreciable disminución de la participación femenina en el trabajo industrial, según los antecedentes que tenemos ... las mujeres representan el $30 \%$ de los trabajadores...

${ }^{66}$ Historia de la Ley 16.434, sesión 8 a del 15 de junio de 1965, Cámara de Diputados. Legislatura Ordinaria, Vol. I, 1965 , p. 924.

${ }^{67}$ Ibid., p. 926.

68 Diputada Correa, Ibid.

${ }^{69}$ En Senado Legislatura Ordinaria 1965, Vol. I, Sesión 33 del Senado 17 de agosto de 1965, pp. 2384-2385.

${ }^{70}$ Informe de la Comisión de Trabajo y Previsión Social, Diario de Sesiones del Senado, sesión 67, pp. 3835-3836. 
De existir causas en la disminución del trabajo femenino, determinadas por estadísticas, éstas se deberían a que el gran porcentaje de mujeres queda al margen de los beneficios previsionales, como, por ejemplo, las trabajadoras a domicilio, las que en sus hogares confeccionan ropas que les envían"71.

El veto al fuero constituyó una ruptura entre los Diputados y los Senadores de la Democracia Cristiana, cuyos Senadores declaraban no estar de acuerdo con las prácticas discriminatorias, pero señalaban que no se podía obligar a los empleadores a contratar mujeres, y por lo tanto "el veto es una cuestión realista y objetiva [...]" la Ley 17.301 consagró el fuero maternal como hoy lo conocemos ${ }^{73}$.

\section{d. La licencia por cuidado infantil}

En la década de los sesenta también se introduce la licencia pagada a las trabajadoras por la enfermedad grave del hijo menor de un año, Ley 17.301 de $1970^{74}$. Esta fue una forma de reconocimiento de las funciones reproductivas y la función social de las mujeres que trabajan remuneradamente. Se le otorgó sólo a la madre considerándose injusto que ella perdiera su trabajo por atender a un hijo enfermo.

En resumen, en este período se produjo un desarrollo normativo que se asemeja a la actual fisonomía del derecho laboral. También se observa cómo la aplicación e interpretación de la ley dio paso a distintas formas de incumplimiento, quizás la primera de ellas es la fórmula de cálculo para la organización de la sala cuna, y con ello el ejercicio del derecho a amamantar/alimentar.

El Departamento Femenino de la Central Única de Trabajadores refería que el 80\% de las empresas no cumplían la obligación de contar con sala cuna, y una de las formas de evadir el cumplimiento de la ley era a través de la contratación de trabajadoras a domicilio $^{75}$. Llama la atención que la demanda provenía de las trabajadoras organizadas y no de todos los trabajadores. No hay antecedentes sobre incumplimiento, y los datos se sistematizaron sólo a partir de los noventa.

${ }^{71}$ Declaración del Departamento Femenino de la Central Única de Trabajadores leída por la Senadora Campusano, Diario de Sesiones, sesión 69, 26 de enero de 1966, pp. 3884-3885.

72 Senador Foncea, Ibid. pp. 3886-3887.

${ }^{73}$ Una revisión actualizada de la discriminación a las trabajadoras y el fuero puede revisarse Riquelme, V., ¿La maternidad castigada? Discriminación y malos tratos, Dirección del Trabajo, Santiago, 2011. Los resultados apuntan que dos tercios de las denuncias a las inspecciones son por no respeto al fuero.

${ }^{74}$ Publicada en el Diario Oficial el 22 de abril de 1970.

${ }^{75}$ Historia de la Ley 16.434, Sesión 69, 26 de enero de 1966, en Senado Legislatura Extraordinaria, Vol. IV $1965-66$, p. 3885. 


\section{El DisCURSO DE LOS NOVENTA: CUIDADO DE LOS HIJOS Y LA COPARENTALIDAD}

El gobierno militar fue un paréntesis en la legislación laboral en que se experimentó una restricción en el ejercicio de derechos. Un ejemplo, es un dictamen de la Dirección del Trabajo de 1978 que señalaba que si bien el fuero continuaba durante todo el tiempo estipulado en la ley, llamaba al empleador a tomar precauciones en la contratación de mujeres para evitar el abuso del derecho. En él se daban instrucciones de cómo hacerlo solicitando copia de certificados de nacimiento, médicos, finiquito y liquidaciones de la trabajadora para establecer si estaba protegida por el fuero o no ${ }^{76}$. La interpretación de la continuidad del fuero independiente del empleador fue dejada sin efecto por la Dirección del Trabajo en otro dictamen de $1991^{77}$.

La dictadura militar fue un retroceso en promoción de los derechos de los trabajadores y letargo respecto de las normas de protección a la maternidad, y en los años 90 una vez recuperada la democracia las transformaciones de las normas amplían ciertos derechos, pues hay conciencia de los problemas que aquejan a las trabajadoras, se avanza con los cambios socioculturales que experimenta el país, y se confieren derechos, aunque limitados, al padre en la primera infancia, se considera a los padres adoptivos, u otros cuidadores y van apareciendo conceptos como apego, paternidad, discriminación. Todo ello lo veremos a la luz de las distintas instituciones.

\section{a. Sala cuna y derecho a alimentación}

Caamaño Rojas sostiene que la interpretación que siguió la Dirección del Trabajo, y agregamos la Contraloría General de la República, que consideraba el derecho a sala cuna y alimentación como interdependientes, era incongruente, ya que no sería acorde con la protección de los derechos fundamentales ${ }^{78}$. En este sentido habría dos tensiones, el número de trabajadoras en relación con la voz 'empresa', 'establecimiento' o 'faena' que utiliza la ley, y luego si este derecho es independiente al derecho a alimentar. Como vimos, hubo un intento para que la Dirección del Trabajo pudiera ordenar la creación de salas cuna en establecimientos con menos de 20 trabajadoras.

La primera modificación fue de 1995, Ley 19.408, cuyo propósito fue hacerse cargo de trabajadoras de centros comerciales imponiendo la obligación de sala cuna cuando tuvieran un contrato de trabajo con un empleador bajo una misma razón social o con

${ }^{76}$ La Revista del Trabajo, No 505, febrero-marzo 1985, pp. 73-75, extracta jurisprudencia sobre la naturaleza personalísima del fuero maternal publicado por Díaz Salas, J., Legislación Social. Código del Trabajo, Tomo XX al XXIV, Editorial Nascimento, Santiago, distintos años. La Dirección del Trabajo bajo un contexto de lo que denomina cesantía agobiante emite el Dictamen $\mathrm{N}^{\circ}$ 2.892, 7 de agosto de 1978, Alcance del Fuero Maternal Establecido en el Artículo 100 del D.L. 2.200, en Revista Jurídica del Trabajo. Oct-Nov 1984, pp. 64-65.

77 Dirección del Trabajo, Dictamen 5.545/174, del 13 de agosto de 1991, en Revista Jurídica del Trabajo 564, Sept. 1991, p. 81.

${ }^{78}$ Caamaño, E., "Comentarios sobre la extensión temporal del derecho a dar alimentos. Nuevo pronunciamiento de la Dirección del Trabajo”, en Revista Laboral Chilena N 122, diciembre 2003, p. 74. 
determinada persona jurídica ${ }^{79}$. Esta norma fue controvertida por su poca claridad o por la imposición de la obligación de sala cuna en centros comerciales a empleadores que no contrataban mujeres ${ }^{80}$, ya que convertía en una especie de solidaridad legal en la distribución de costos de la reproducción. Es decir, el discurso del Diputado Monckeberg en los sesenta no caló ni en empresarios ni entre algunos laboralistas.

Posteriormente la Ley 19.591 de 1998 establece, entre otras modificaciones, el derecho a sala cuna para todas las mujeres de aquellas empresas con más de 20 trabajadoras, independiente donde se encuentren las faenas o establecimientos ${ }^{81}$.

Thayer y Novoa, a propósito de la reglamentación relativa a salas cuna, sostienen que la obligación "debiera gravitar hacia la seguridad social y no implicar un recargo en los costos para el empleador o la empresa, pues ello conspira contra la igual opción al trabajo de la mujer" 82 . En efecto, la existencia de normas que gravan a las empresas con obligaciones de seguridad social, como sería la sala cuna, produce en la práctica un efecto negativo al otorgar un trato diferenciado a las mujeres de acuerdo al tamaño de la empresa. La Corte Federal de Alemania declaró inconstitucional una ley de 1997 que disponía que el seguro de enfermedad debía ser de costo de los empleadores en las prestaciones de protección de la maternidad, y que subsidiaría a las pequeñas empresas ${ }^{83}$. El objetivo de la política pública era ampliar el acceso de la inserción laboral de las mujeres en las pequeñas empresas, pero el resultado producía discriminación indirecta, ya que desincentivaría la contratación de mujeres en empresas medianas y grandes ${ }^{84}$. El Comité de Expertos de la OIT consideró que la norma debía modificarse.

La última modificación es la dictación de la Ley 20.166 de 2007 que independiza los derechos de sala cuna y alimentación, de tal manera que la trabajadora pueda ejercer el segundo aun cuando el empleador no esté obligado a contar con una sala cuna. Introduce flexibilidad en los tiempos de ejercicio del derecho a alimentación, de tal forma que pueda organizarse armónicamente con los derechos de las trabajadoras y el buen servicio de la empresa, acumulando el tiempo para alimentar, ya retrasando, adelantando la jornada o fraccionando este tiempo. Esta fue una moción presentada por Diputados y Diputadas de diversos partidos en $1995^{85}$. Esta es la primera vez que se

79 Publicada en el Diario Oficial en 29 de agosto de 1995.

${ }^{80}$ Jiménez, G., "Salas cuna en centros comerciales. Dificultades de aplicación del nuevo inciso primero del artículo 203 del Código del Trabajo”, en Revista Jurídica del Trabajo, enero de 1996, pp. 76-79.

${ }^{81}$ Publicada en el Diario Oficial, 9 de noviembre de 1998.

82 Thayer, W. y Novoa, P., Manual de Derecho del Trabajo. Tomo IV. Derecho Individual de trabajo (continuación) y Derecho procesal del trabajo, $4^{\mathrm{a}}$ ed. actualizada, Editorial Jurídica de Chile, Santiago, 2003, p. 155.

${ }^{83}$ Observación (CEACR)-Adopción: 2009, Publicación: 99a reunión CIT (2010) Convenio sobre la protección de la maternidad, 1919 (núm. 3)-Alemania (Ratificación : 1927). En: http://www.ilo.org/dyn/normlex/es/f?p =1000:13100:218019530992306:NO:13100:P13100_COMMENT_ID,P11110_COUNTRY_ID,P11110_ COUNTRY_NAME,P11110_COMMENT_YEAR:2321247,102643,Alemania, 2009.

${ }^{84}$ Ibid.

${ }^{85}$ Diputados Isabel Allende B., Rubén Gajardo Ch., Alejandro Navarro B., Aníbal Pérez L., Fanny Pollarolo V., Marina Prochelle A., Exequiel Silva O., Edmundo Villouta C. y Martita Wörner T., el 23 de noviembre, 1995. Cuenta en Sesión 25, Legislatura 332. En: Historia de la Ley 20.166. 
articula de manera consistente un discurso de lactancia y tiempos de cuidado con la salud mental de la mujer.

El proyecto se centró en dos aspectos centrales: la transgresión al espíritu de la ley y la Constitución, y se alude a la protección "de la vida y la salud del menor, sin desmedro además de la tranquilidad física y mental de la madre" ${ }^{86}$, debiendo ser igual la protección legal de mujeres y niños ante la misma situación. Los parlamentarios argumentaron que dada la interpretación imperante de la Dirección del Trabajo que vinculaba los dos derechos tenía un efecto discriminatorio en los niños y en la salud mental de las mujeres, pues hacía depender el ejercicio de uno (alimentar) en la existencia del otro (sala cuna) ${ }^{87}$. Como argumentó el Senador Navarro (PS), la propuesta constituye un trato igualitario para los niños independiente del lugar y condiciones en las cuales sus madres trabajen ${ }^{88}$.

Se relevó que la interpretación de la Dirección del Trabajo creó incentivos negativos en la contratación de mujeres, pero además expresó que asegurar estos derechos constituía un bien social, protegía el rendimiento y productividad. Es interesante observar cómo el discurso de los sesenta del rol social del Estado vuelve en los noventa, y se entrecruza con las nuevas miradas que imperan en el país y que resultarían más convincentes: la productividad.

El Senador De Urresti (PS) expresó que "Es importante que los empresarios entiendan que este derecho es una inversión en tranquilidad social. La madre trabajadora que puede amamantar a su hijo durante el día va a producir mejor, pues estará más tranquila por el hecho de que su hijo está sano y cuenta con su afecto y su contacto... Debemos establecer la posibilidad de que toda empresa tenga sala cuna y no sólo aquellas que ocupan veinte o más trabajadoras. ¿Por qué una empresa con 19 trabajadoras se ve impedida de contar con este beneficio?" 89 .

En este marco, se discuten los costos de la maternidad; la Senadora Allende (PS) señala "que no es posible que la mujer siga pagando los costos de la maternidad [...] Desde hace muchos años, varios de nosotros hemos venido levantando la voz para decir que la maternidad significa una responsabilidad de pareja, del hombre y de la mujer. Asimismo, hemos dado a conocer la dificultad que representa para las mujeres hacerse cargo de la maternidad en forma exclusiva..." 90 . En este sentido, se observa un vuelco, la equidad de género en el cuidado infantil que avanza en la idea de que sea una obligación de todos, pero aún no está asentada que sea una responsabilidad pública en la cual todos participen. Las modificaciones resultan un avance, pero, en los hechos, las propuestas no apuntan a establecer derechos respecto de trabajadores con responsabilidades familiares, sino que están sólo asociadas a las trabajadoras. Caamaño a su vez critica que las normas no sean interpretadas con el fin que persiguen y se realice una lectura literal

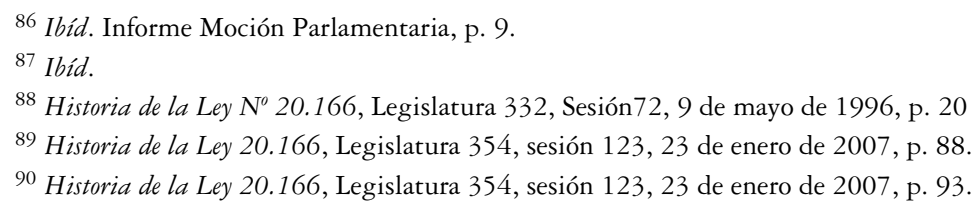


que no permitan ni siquiera el ejercicio adecuado del derecho cuando hay más de un niño al cual alimentar ${ }^{91}$.

La brecha entre derecho y realidad queda de manifiesto en los resultados de la Encuesta ENCLA de 1999 que mostraba que el 28\% de las empresas no cumplía con la obligación y que casi un $20 \%$ lo hacía por vías no permitidas, según las respuestas de los empleadores ${ }^{92}$. Los datos indicaban que menos del $5 \%$ de las trabajadoras que teniendo el derecho a la sala cuna lo ejercían ${ }^{93}$. Si la formulación en el cumplimiento de una norma, sea de sala cuna o alimentación no considera las reales condiciones de vida y trabajo de las mujeres, entonces se convierte en un derecho que no es ejercido. Si la obligación de un empleador es formulada en términos rígidos, en la práctica se desincentiva que el derecho se haga realidad.

Coincidimos con la crítica de Pieper Mooney que desde el inicio no se consideraron los contextos en los que se deben aplicar las normas. La legislación ha introducido la flexibilidad que se produjo por la vía de los hechos, el pago del bono. No obstante, cifras actualizadas de la Encuesta ENCLA 2008 muestran que sólo un 8,4\% de las empresas están obligadas a pagar la sala cuna y un $36 \%$ no cumple con la obligación en ninguna de las fórmulas que hoy se permiten ${ }^{94}$.

Para asegurar la protección de los derechos cobra relevancia el rol fiscalizador del Estado. Sin duda, una de las mejores formas de fiscalización es la exigencia de derechos por parte de los trabajadores, pero en contexto de crisis económica y de un esquema flexible de despido se relativiza o limita la exigencia de los derechos.

\section{b. La tarea del cuidado infantil y la corresponsabilidad}

Desde los noventa se presentan propuestas que incorporan paulatina aunque superficialmente a los hombres y a otras personas en tareas de cuidado de los niños.

La Ley 19.250 de 1993 otorga, entre otros, la posibilidad de que el padre también pueda gozar de una licencia pagada por la enfermedad grave del hijo, pero solo si la madre así lo decide ${ }^{95}$. Al padre se le otorga el derecho de gozar del permiso de postnatal y el subsidio correspondiente en caso de que la madre hubiera fallecido, o si es que tuviera la tuición del niño. Igualmente se le otorga el derecho a licencia a madres o padres adoptivos, o en proceso de serlo, o a otras personas que sean las cuidadoras de un menor siempre y cuando tuvieran la tuición judicialmente decretada, o una medida de protección a su favor.

${ }^{91}$ Caamaño, E., op. cit., p. 75.

92 Espinoza, M. y Damianovic, N., Encuesta ENCLA 1999. Informe de Resultados, Dirección del Trabajo, Santiago, 2000, p. 46. En: http://www.dt.gob.cl/documentacion/1612/articles-62786_recurso_1.pdf

93 Ibid.

${ }^{94}$ Díaz, E y Mella, P., ENCLA 2008. Inequidades y brechas de género. Informe de Resultados, Dirección del Trabajo, Santiago, 2009, pp. 108 y 110. En: http://www.dt.gob.cl/documentacion/1612/articles-97629_recurso_1.pdf.

${ }^{95}$ Publicada en el Diario Oficial el 30 de septiembre 1993. 
El mensaje de esta reforma expresa que recoge "una tendencia cultural que se expande progresivamente en torno al rol de la pareja y su corresponsabilidad en el cuidado de los hijos, elimina una posible fuente de discriminaciones y reconoce en plenitud el similar rango e importancia del trabajo de la mujer en relación con el de su pareja" 96 . El ministro del Trabajo y Previsión Social señala que se trata que el cuidado sea una tarea compartida ${ }^{97}$.

Detrás de esta modificación hay un discurso político que impulsa cambios culturales en la redistribución de los roles en el cuidado y crianza de los hijos. Se identificarán necesidades de mayor protección de la maternidad desde una mirada de equidad de género y que se manifestó en la reciente discusión de la extensión del postnatal ${ }^{98-99}$.

La equidad en el cuidado quedó plasmada en la Ley 19.505 que establece un permiso especial a trabajadores (madre y padre) en caso de enfermedad grave o terminal de un hijo menor de 18 años equivalente a 10 jornadas laborales en un año que pueden fraccionarse en horas a elección del padre o madre ${ }^{100}$. Iniciada con un mensaje presidencial en la búsqueda de analogar la situación de enfermedad grave del menor de un año, esta permite el permiso que pueda compensarse posteriormente por el trabajador/a ${ }^{101}$.

La discusión muestra la evidencia médica sobre el acompañamiento de los padres y la lactancia durante la hospitalización. No obstante, hubo desacuerdos. El Senador Prat (UDI) expresó "que no concurriría a aprobar el proyecto en general, puesto que este tipo de normas y otras de similar naturaleza deben ser objeto de un acuerdo de la voluntad de las partes, sea a través de un convenio colectivo o de la relación directa entre el trabajador y su empleador. [...Y que son] dañinas para las propias relaciones laborales"102.

Aparecen también argumentos que acogen el proyecto, pero en base a un discurso sobre la indefensión de los hijos producto de la inserción de las mujeres en el mercado laboral; un efecto no deseable, el Senador Valdés (DC) postula que es una realidad nueva cuando sus propias correligionarias ya lo habían dicho en los sesenta,

${ }^{96}$ Historia de la Ley 19.250, Mensaje del Ejecutivo, 21 de mayo de 1991, Legislatura 322, sesión 1, p. 4.

${ }^{97}$ Intervención del Ministro Cortázar, Ibíd. 14.

98 Cecily Halpern, señala que "políticas gubernamentales de corresponsabilidad parental, orientadas a que ambos padres puedan concordar los roles familiares y laborales, mediante el necesario cambio cultural, primeramente en el plano de las ideas y actitudes, y luego, en el plano normativo". Halpern, Cecily, "La mujer en el trabajo y la familia: roles en conflicto", en Rev. Actualidad Jurídica, No 24, 2011, pp. 49 y 51.

${ }^{99}$ En 2007, Caamaño sostenía: "Evidente que se requiere incorporar en nuestra legislación laboral disposiciones que den posibilidad de desarrollo equitativo a la demanda de compatibilización de trabajo y vida familiar, pues salvo el permiso parental (...) no existe una regulación sistemática, ni una política social continua y coherente que contribuyan a hacer realidad de manera efectiva la igualdad de oportunidades laborales entre hombres y mujeres", Caamaño, E., "Oportunidades de conciliación de trabajo y vida familiar en la legislación laboral chilena", en: Revista de Derecho de la Pontificia Universidad Católica de Valparaíso No XXIX, 2007, p. 198. Véase también, Caamaño, E., Mujer, trabajo y derecho, Abeledo Perrot, Santiago, 2011.

${ }^{100}$ Publicada en el Diario Oficial de 25 de julio de 1997.

101 Boletín 1831-13 de 10 de abril de 1996. Historia de la Ley 19.505, pp. 5-6.

${ }^{102}$ Historia de la Ley 19.505, Informe de la Comisión de Trabajo del Senado, 1 de abril de 1997, p. 41. 
"[...]la iniciativa en debate atiende una necesidad que no podría haber sido discutida igualmente hace 30 años-, como es la masiva incorporación de las mujeres al ámbito laboral, por cuya razón los hijos quedan desprotegidos, ya que el padre y la madre trabajan. ... legislación de los años 40, eran muy pocas las mujeres que realizaban labores fuera del hogar. La mayoría eran dueñas de casa. Hoy -para bien 0 para mal-casi todas las mujeres trabajan, y uno de los grandes problemas derivados de ese hecho es el abandono en que quedan los hijos" ${ }^{103}$. [el énfasis es nuestro]

La última reforma en este camino fue la Ley 20.047 (2005) que establece el permiso paternal irrenunciable pagado de cuatro días en caso de nacimiento de un hijo o adopción, lo cual sumado al día legal existente por nacimiento le otorga al padre cinco días de asueto. Esta ley de iniciativa parlamentaria tuvo por objetivo corregir una situación de discordancia ya que la Constitución Política de la República consagra en su artículo primero que la familia es el núcleo fundamental de la sociedad ${ }^{104}$.

El proyecto se fundamenta en la conciliación entre el trabajo y la familia, la que no se recoge en las normas protectoras de la maternidad, pues, en general, no alcanzan al padre y le impiden tener contacto con el hijo interrumpiendo el proceso que el padre ha tenido durante el embarazo ${ }^{105}$; aparece así en el discurso un hombre/padre idealizado:

“contradiciendo las acciones que los padres realizan participando en su gran mayoría en todo el proceso de embarazo de la mujer, concurriendo a los controles periódicos, ingresando al momento del parto propiamente tal, etc.:, pero al momento del nacimiento solamente pueden estar algunas horas ya que deben volver a trabajar, rompiendo bruscamente todo un proceso lógico y natural y que se ve interrumpido por estos vacíos de la ley, precisamente en el momento que tanto la madre como la criatura necesitan de una mayor atención y cuidados que redundarán en lazos de mayor afecto y afiatamiento del núcleo familiar" 106 .

El Ejecutivo apoya la idea de legislar y apunta al cambio cultural en los roles de crianza y cuidado; la Ministra del Servicio Nacional de la Mujer expresa que las responsabilidades frente al nacimiento de hijos o hijas deben ser asumidas en conjunto por los progenitores y que la propuesta favorece la inserción de la mujer en el mundo del trabajo ${ }^{107}$.

Por su parte, el Diputado Salaberry (UDI) reconoce que los hombres escasamente se involucran en el parto, el control del embarazo y posteriormente en los controles

${ }^{103}$ Historia de la Ley 19.505, Discusión en Sala, Senado, 8 de abril 1997, p. 54.

${ }^{104}$ Historia de la Ley 20.047, moción parlamentaria de los Diputados Ramón Barros, Marcela Cubillos, Julio Dittborn, Camilo Escalona, Marcelo Forni, Pablo Longueira, Iván Norambuena, Felipe Salaberry, Boris Tapia y Gonzalo Uriarte, 31 de julio de 2003. Cuenta en Sesión 23, Legislatura 349, p. 4.

${ }^{105}$ Ibid., p. 4.

106 Ibid.

${ }^{107}$ Ibid., p. 5. 
pediátricos y las tareas de crianza y cuidado, ya que las mujeres realizan el $95 \%$ de esas tareas, constituyendo todo ello un barrera social y cultural para el ingreso al mundo laboral de las mujeres ${ }^{108}$, y que la participación de los hombres al momento del nacimiento está cruzada por razones económicas ${ }^{109}$. No obstante, seis diputados votaron en contra de la idea de que este derecho fuera irrenunciable ${ }^{110}$.

En el debate legislativo se entrecruzan los aplausos para avanzar en la equidad de género, Diputada Muñoz (PPD) ${ }^{111}$, y el reconocimiento de que no es la equidad sino la protección de los derechos de la infancia como lo sostuvo el Diputado Juan Pablo Letelier (PS $)^{112}$. Así, se sitúa esta discusión en las tensiones existentes entre el mercado de trabajo y las exigencias de parte de empresarios para costos para las empresas, y por otro, la compensación que se produciría teniendo trabajadores más felices y por consiguiente el aumento de la productividad ${ }^{113}$. Se deslava la equidad de género como un argumento, pero va instalando paulatinamente en la discusión de pensar las reformas desde un cuidador universal, y asumir que el cuidado no es sólo tarea de la mujer sino de toda la sociedad ${ }^{114}$.

Entre las últimas modificaciones al Código del Trabajo, Ley 20.399 de 2009, extiende el derecho del padre a gozar del derecho a sala cuna, si él tiene la tuición del hijo, o la madre hubiera fallecido. La ley incorpora a otros cuidadores del niño que pudieran tener los mismos derechos, no siendo ni los padres ni madres biológicos. La corresponsabilidad en cuanto discurso se reflejó de mejor manera en la norma que extiende el postnatal.

\section{CONCLUSIONES}

Las tensiones y los problemas o consecuencias en la relación maternidad y trabajo han estado presentes durante el siglo, replicándose en las distintas décadas con una lógica de atemporalidad y con algunas modificaciones de énfasis en los discursos. Estas tensiones, luego se replican como problemas en distintos ámbitos del trabajo y la maternidad. Otras claramente son temas emergentes y que dan cuenta de los cambios sociales que ha experimenta la sociedad en los últimos cien años.

La introducción de las normas deja también al descubierto las formas en que se evita el cumplimiento de las mismas. Los empleadores respetaron la ley, pero no su espíritu,

\footnotetext{
${ }^{108}$ Ibid., Legislatura 351, Sesión 43, 15 de septiembre de 2004, p. 11.

109 Intervención del Diputado Barros, Ibíd. p. 16.

${ }^{110}$ Los Diputados Bayo, Bertolino, Delmastro, Galilea (José Antonio), Hidalgo y Vilches, p. 44.

${ }^{111}$ Ibid., Intervención de la Diputada Adriana Muñoz, pp. 16-17.

112 Historia de la Ley 20.047, Intervención del Dip. Juan Pablo Letelier, p. 34.

113 Informe a la Comisión de Trabajo y Previsión Social del Senado, Sesión 44, Legislatura 352, 11 de

${ }^{114}$ Ibíd., Legislatura 353, Sesión 27, 25 de agosto de 2005, p. 100. Es interesante rescatar en este punto el trabajo de Nancy Fraser, en Iustitia Interrupta. Reflexiones críticas desde la posición post socialista, trad. Magdalena Olguín y María Isabel Jaramillo, Siglo de Hombre Editores y Universidad de los Andes, Bogotá, 1997, pp. 55-92.
} abril de 2005, p. 50. 
ello fue con la anuencia de los órganos del Estado que restringieron los derechos a través de la interpretación para reducir los costos a los empresarios y al Estado-empleador. Se consagraban disposiciones que obligaban, por ejemplo, al pago de la sala cuna, pero se restringió con asumir el número de trabajadoras por "lugar de trabajo" y no por trabajadoras contratadas por el empleador.

Otras formas de evasión se han hecho históricamente a través de formas de contratación que dejaban fuera de la órbita de protección a las trabajadoras, como el trabajo domiciliario, hoy se manifiesta en los contratos de servicios a honorarios, incluso en la administración pública de empleadas sujetas a dependencia y subordinación. Esta trayectoria evidencia el incumplimiento de las normas de protección a la maternidad.

Se constata que las normas de protección a la mujer trabajadora han sido un vehículo para proteger la infancia, la familia, la sociedad toda (el bien común), pero escasamente para proteger a la mujer en cuanto sujeto de protección como ciudadana.

La mera posibilidad de normas de protección a la maternidad y posteriormente su extensión siempre han sido resistidas. Hay argumentos que cruzan distintas épocas como lo perjudicial que son para la empleabilidad de las mujeres el encarecimiento de los costos de la mano de obra, que limita la gestión de recursos humanos en la empresa y que el trabajo remunerado femenino constituye un mal menor pues abandona las tareas de cuidado y crianza. A este discurso empresarial se suma el discurso biomédico que busca la protección de la infancia a través de la lactancia. Este es un denominador común de todas las modificaciones sobre el descanso maternal. Es un argumento que cala profundo, pero que ha cedido ante la noción de apego que debe tener el padre con sus hijos. La exigencia de equidad en el acceso al empleo aparece como un discurso reciente, y se acopla a la exigencia de los mismos derechos que tienen las mujeres frente a la maternidad para los padres, y otros cuidadores.

Todavía nos falta articular un discurso coherente que mire la relación de conciliación de familia y trabajo que integre igualmente a hombres y mujeres, ya que la conciliación no es sólo tarea de las mujeres.

\section{BIBLIOGRAFÍA}

Biblioteca del Congreso Nacional. Historia de la Lei 3.186. Diario de Sesiones. Historia del Decreto Lei 442. Diario de Sesiones. Historia de la Ley 16.434. Diario de Sesiones. Historia de la Ley 16.511. Diario de Sesiones. Historia de la Ley 17.301. Diario de Sesiones. Historia de la Ley 17.928. Diario de Sesiones. HiSTORIA de la Ley 19.250. En: http://www.bcn.cl/ HISTORIA de la Ley 19.505. En: http://www.bcn.cl/ HISTORIA de la Ley 20.047. En: http://www.bcn.cl/ HiSTORIA de la Ley 20.166. En: http://www.bcn.cl/ HisTORIA de la Ley 20.367. En: http://www.bcn.cl/ 
CaAmaño, E., "Comentarios sobre la extensión temporal del derecho a dar alimentos. Nuevo pronunciamiento de la Dirección del Trabajo”, en: Revista Laboral Chilena N ${ }^{\circ} 122$, diciembre 2003 .

CaAmaño, E., "Oportunidades de conciliación de trabajo y vida familiar en la legislación laboral chilena", en: Revista de Derecho de la Pontificia Universidad Católica de Valparaíso N XXIX, 2007.

CAAmAÑo, E., La necesidad de incluir al padre en los derechos para la conciliación de trabajo y vida familiar, Revista Laboral Chilena, julio 2009.

Mujer, trabajo y derecho, Abeledo Perrot, Santiago, 2011.

Díaz Salas, J., Legislación Social. Código del Trabajo, Tomo V 1949-1951, Editorial Nascimento, Santiago, 1952.

DíAz SALAS, J., Legislación Social. Código del Trabajo, Tomo VIII 1956-1957, Editorial Nascimento Santiago, 1958.

DíAz SALAs, J., Legislación Social. Código del Trabajo, Tomo XX al XXIV, Editorial Nascimento, Santiago:, (diferentes años).

Díaz, E. y Mella, P., Encuesta ENCLA 2008. Inequidades y brechas de género. Informe de resultados, Dirección del Trabajo, Santiago, 2009. En: http://www.dt.gob.cl/documentacion/1612/articles-97629_recurso_1.pdf.

Dides, C., Benavides ET AL., Salud Sexual y Reproductiva en Chile 2007: actualización de datos estadísticos, Facultad Latinoamericana de Ciencias Sociales, Santiago, 2008.

Espinoza, M. y Damianovic, N., Encuesta ENCLA 1999. Informe de resultados. Dirección del Trabajo, Santiago, 2000. En: http://www.dt.gob.cl/documentacion/1612/articles-62786_recurso_1.pdf

Fraser, N., Iustitia Interrupta. Reflexiones críticas desde la posición post socialista, trad. Magdalena Olguín y María Isabel Jaramillo, Siglo de Hombre Editores y Universidad de los Andes Bogotá, 1997.

Halpern, C., "La mujer en el trabajo y la familia: roles en conflicto", en: Rev. Actualidad Jurídica $\mathrm{N}^{\circ} 24,2011$.

Hutchison, E., Mujeres, trabajo y maternidad: género y consenso legislativo, Las labores propias del Sexo. Género, políticas y trabajo en el Chile urbano, 1900-1930, LOM, Santiago, 2006.

Instituto Nacional de Estadísticas, Compendio Estadístico de Género. Publicaciones del Instituto Nacional de Estadísticas desagregadas por sexo (2007-2009) 2010, Santiago, 2011.

Instituto NaCional de Estadísticas, Encuesta Exploratoria ¿Cómo distribuyen el tiempo hombres $y$ mujeres?, Santiago, 2009.

JimÉneZ, G., "Salas cunas en centros comerciales. Dificultades de aplicación del nuevo inciso primero del artículo 203 del Código del Trabajo", en: Revista Jurídica del Trabajo, enero de 1996.

Molina, C., Institucionalidad Sanitaria Chilena 1889-1989, LOM, Santiago, 2010.

Pieper Mooney, J., The Politics of Motherhood. Maternity and women's rights in twentieth-century Chile, The University of Pittsburgh Press, Pittsburgh, 2009.

Programa de las Naciones Unidas para el Desarrollo, Desarrollo humano en Chile. Género: los desafíos de la igualdad 2010, Santiago, 2011.

Riquelme, V., ¿La maternidad castigada? Discriminación y malos tratos, Dirección del Trabajo, Santiago, 2011.

Rojas Miño, I., Manual de Derecho del Trabajo. Derecho Individual, LexisNexis, Santiago, 2004.

SALAZAR, G., Labradores, peones y proletarios. Formación y crisis de la sociedad popular chilena, LOM, Santiago, 2000.

Salazar, G. y Pinto, J., Historia Contemporánea de Chile IV. Hombría y Feminidad, LOM, Santiago, 2002. 
SCHIAPpaCasse, V. ET AL., Chile: situación de la salud y los derechos sexuales y reproductivos, Instituto Chileno de Medicina Reproductiva, Corporación de salud y Políticas sociales, Instituto Chileno de Medicina Reproductiva y Servicio Nacional de la Mujer, Santiago, 2003.

Thayer, W. y Novoa, P., Manual de Derecho del Trabajo. Tomo IV. Derecho Individual de trabajo (continuación) y Derecho procesal del trabajo, Cuarta edición actualizada, Editorial Jurídica de Chile, Santiago, 2003.

Leyes

República de Chile. Lei 3.186. Publicada en el Diario Oficial 13 de enero de 1917.

- Decreto Lei 442. Publicado en el Diario Oficial 6 de abril de 1925.

- Decreto con Fuerza de Ley 178. Publicado en el Diario Oficial 28 de mayo de 1931.

- $\quad$ Ley 16.434. Publicada en el Diario Oficial el 8 agosto de 1952.

- Ley 16.511. Publicada en el Diario Oficial el 26 de julio de 1966.

- $\quad$ Ley 17.301. Publicada en el Diario Oficial el 22 abril de 1970.

- Ley 17.928. Publicada en el Diario Oficial el 10 de mayo de 1973.

- $\quad$ Ley 19.250. Publicada en el Diario Oficial el 30 de septiembre 1993.

- Ley 19.505. Publicada en el Diario Oficial el 25 de julio de 1997.

- Ley 20.047. Publicada en el Diario Oficial el 2 de septiembre de 2005.

- $\quad$ Ley 20.166. Publicada en el Diario Oficial el 12 de febrero de 2007.

- $\quad$ Ley 20.367. Publicada en el Diario Oficial el 7 de agosto de 2009.

Dirección del Trabajo, Dictamen N 2.892 del 7 de agosto de 1978, Alcance del Fuero Maternal Establecido en el Artículo 100 del D.L. 2.200, en: Revista Jurídica del Trabajo, Oct- Nov 1984. Dictamen 5.545/174 del 13 de agosto de 1991 en: Revista Jurídica del Trabajo 564, Sept. 1991. 


\section{Cuadro Sinóptico de las Modificaciones Legales sobre Protección a la Maternidad}

\begin{tabular}{lll}
\hline Año & Regulación & Materia \\
\hline 1917 & Ley 3.186
\end{tabular}

1917 Ley $3.186 \quad$ Empleador tiene la obligación de establecer sala cuna y el derecho a dos porciones de tiempo para lactancia en fábricas o establecimientos de más de 50 trabajadoras mayores de 18 años.

1925 Decreto 442 Descanso Maternal de 60 días (40 y 20) pagado por el empleador de $50 \%$ del salario. Inamovilidad por el tiempo del descanso.

1931 Código Laboral Extensión del derecho a sala cuna y lactancia:

D.F.L. 178 Cubre a todas las mujeres sin distinción de edad y estado civil y reduce a 20 el número de mujeres para que nazca obligación.

Extensión del descanso maternal a 12 semanas: 6 antes y 6 después del parto. El pago de la licencia (equivalente al $50 \%$ del salario) se divide entre empleador y sistema de seguridad social.

1952 Ley 10.883 Pago de subsidio de maternidad equivalente al promedio de remuneraciones pagado por el sistema previsional.

Las obreras podrán extender el postnatal por razones médicas del niño en la Ley del Seguro Obrero.

1966 Ley 16.434 Confiere un postnatal ampliado en el Código del Trabajo sujeto la discreción a los servicios de salud para atender la salud del recién nacido.

1966 Ley 16.511 El derecho a sala cuna y lactancia es extendido hasta que el niño cumpla dos años.

La Inspección del Trabajo puede ordenar crear salas cunas en establecimientos con menos de 20 trabajadoras.

1970 Ley 17.301 El Código del Trabajo señala que las dos porciones de tiempo son para alimentar al hijo menor de 2 años.

Se establece la licencia pagada a la madre por la enfermedad grave del hijo menor de un año.

Extensión del fuero maternal a un año desde el cese del postnatal.

1972 Ley 17.928

Se extiende el descanso maternal a 18 semanas.

1993 Ley 19.250 El padre podrá gozar de la licencia por enfermedad de hijo menor de un año, si la madre lo decide. El padre tiene derecho en caso de que madre hubiere fallecido o el padre tuviera la custodia legal del niño.

1995 Ley 19.408 Las trabajadoras de centros comerciales que tienen relación laboral con una misma empresa o bajo una misma razón social tienen derecho a sala cuna.

1998 Ley $19.591 \quad$ El empleador está obligado a pagar sala cuna si emplea 20 o más trabajadoras independiente de las faenas o establecimientos que tenga.

1997 Ley 19.505 Permiso parental en caso de enfermedad grave a hijo menor de 18 años.

2000 Ley $19.670 \quad$ Otorga el derecho al descanso y subsidio al padre en caso de fallecimiento de la madre.

2005 Ley 20.047 Licencia parental por el nacimiento o adopción de un hijo.

2007 Ley 20.166 El derecho a alimentar es extendido a todas las trabajadoras independientemente del derecho a sala cuna.

2009 Ley 20.367 Otorga licencia, subsidio y fuero a las madres adoptantes de hijo mayor de seis meses

2009 Ley $20.399 \quad$ El padre que tiene la tuición o cuidado del hijo tiene derecho a sala cuna. 
